\title{
Gas-protective efficiency of strips of green plantings on objects of transport infrastructure
}

\author{
Vladimir Sidorenko, Vladimir Balakin*, Aleksei Antyufeyev and Georgi Kuznetsov \\ Volgograd State Technical University, Volgograd, 400074, Russia
}

\begin{abstract}
Defining the geometrics and structure of linear and strip composite urban green belts of aesthetic and environment-protection functions intended for transportation infrastructure facilities in urban planning zones and historic centers in densely built-up areas intensely used by transportation services. The observations were made in streets of major cities and on physical models of buildings and green belts of three degrees of density, from dense to permeable. The dependence of air-pollutant shielding efficiency of green belts on their density and height has been determined. Vertical concentration fields on the street cross-section have been obtained by physical modeling, and consistent patterns of car emissions dispersion by shelterbelts of various structure have been found. The lowest car emissions concentration behind green belts is observed at a distance equaling $h$ (belt height) to $1,5 h$, where the pedestrians move; the highest, at a distance of $2 h$ to $3 h$. To effectively protect the pedestrian ways and the areas along the road from car emissions, dense and evenly semi-open shelterbelts, 15 to $30 \mathrm{~m}$ wide should be used. If the width of the road dividing strip is limited, shelterbelts with the openness factor of 0,5 to 0,6 should be used. The plant rows closest to the road should consist of shrubbery making a two-storey hedge, and of low-crown trees, with the further rows increasing in height.
\end{abstract}

\section{Introduction}

When organizing the plantation objects in the transport infrastructure objects where the "linear forms of pollution" are mostly observed [1], linear-strip structures of green plantations have appeared in the form of alternating solid planes in the type of rectilinear, curvilinear, and also located along a zigzag line "walls" separating the residential area from the carriageway [2]. However, the "techniques and traditions in urban greening, as well as the landscape-aesthetic principles of their design" have not yet fully provided ecological well-being and comfort in residential area [3].

Trees and shrubs, unlike impenetrable elements of landscaping and buildings, are partially permeable obstacles, behind which there is a mixing of two turbulent jets - passing through the barrier and enveloping it [4]. Due to this aerodynamic property, the reduction in the level of air pollution by the green plantations roadside belt occurs in part by the absorption of individual components of the car exhaust [5], and also - mainly - due to their dispersion in the surrounding space flowing from above air stream [6].

\footnotetext{
*Corresponding author: balakin-its@yandex.ru
} 
Out of the available experimental data, it follows that the leading role in the air flow transformation through the tree belt area is played by the trees' height, crown shape and density, nature of stem, dendrological composition of plants [4, 6]. In such a case, belts' wind-protecting effect directly depends not on their width, but on the trees and shrubs density. In the field-protective forestation, this feature of the forest belts makes it possible to reduce to a certain minimum their width and area on the slopes without a noticeable weakening of wind protection effectiveness [7].

In this connection, a similar task arises to study the green plantations linear-strip structures geometric characteristics and design features influence on the wind transformation and the car emissions dispersion in urban streets, the width of which along building lines, regulated by building codes, allows the formation of greening belts with a limited number of woody plants rows.

\section{Research methods}

The research on the green plantations gas-protective functions was carried out on the streets of large cities and the range of large-scale modeling [8-10] using the models of belts of tree and shrub plantations of dense, openness and blown structures, which characteristics are given in the papers by Ya.A. Smalko [6] and F.L. Serebrovsky [4]. The models were metal wire frames made at a scale of 1:20 and filled to a given density with a synthetic fiber.

Previously, for each belt, the coefficient of openness $(K)$ was determined as the ratio of the area of obstacles in the path of the car exhaust distribution - the elements of the framework and the synthetic material - to the total area of its frontal projection. For this, the models were photographed against a light background, and then the resulting negatives were placed in a photoelectric colorimeter ФЭК-56 camera. The coefficients of the belt openness were determined by comparing the optical densities of the models negatives and the impermeable screen. The same method was used to establish the openness coefficients of the greening belts in full-scale conditions.

A specially designed pipeline simulating the transport flow was used as a linear source of car exhaust.

Air samples were taken at the point grid nodes on a cross-section to the source section, with a step at height of $1.5 \mathrm{~m}$ at horizontal distances. As the result of the samples chemical analysis, carbon monoxide $(\mathrm{CO})$ concentration fields in the vertical plane were obtained in the open area and according to the scheme "carriageway - green strip".

\section{Results and Discussion}

From the experimental results, it follows that in the open space conditions, the most intense car exhaust dispersion occurs exponentially in the limits of a roadside belt of width up to 30 $\mathrm{m}$. Further decrease in the ingredients content in the air follows a linear law. In accordance with this, $\mathrm{CO}$ concentration (in $\mathrm{mg} / \mathrm{m}^{3}$ ) in the direction perpendicular to the road can be calculated by the formulas:

$$
\begin{gathered}
\text { at } x \leq 30 m \quad q_{x}=q_{0} \mathrm{e}^{-0,0413 x} \\
\text { at } x>30 m \quad q_{x}=0,29 q_{0}-0,14(x-30)
\end{gathered}
$$

where $x$ is the distance from the edge of the carriageway to the calculated point, $\mathrm{m} ; q_{0}$ is the initial concentration of $\mathrm{CO}$ at the edge of the carriageway at the height of $1,5 \mathrm{~m}, \mathrm{mg} / \mathrm{m}^{3}$. 
Fig. 1 shows the isolines of $\mathrm{CO}$ concentration behind the greening belts of the blown and dense structures as mechanical barriers in the path of the gas-air flow. In both cases, the lowest level of atmospheric air pollution is observed directly behind the belt - in the areas of pedestrian traffic. The maximum gas contamination is noted in the zone where the plume touches the earth's surface at a distance of $2 . . .3$ belt heights. The nature of the isolines confirms the above provision that green plantations are semipermeable screens that divert some of the contamination into the upper atmosphere and disperse it. In this case, its another part can be absorbed by a greening belt when the gas-air mixture passes through the branches and leaves [5].

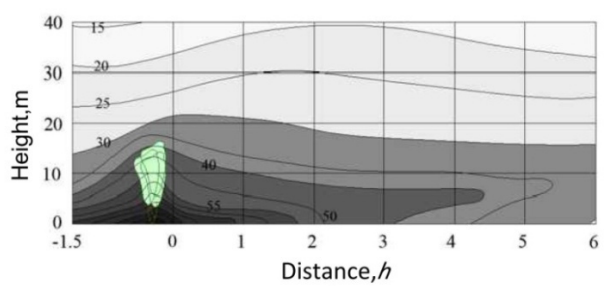

a

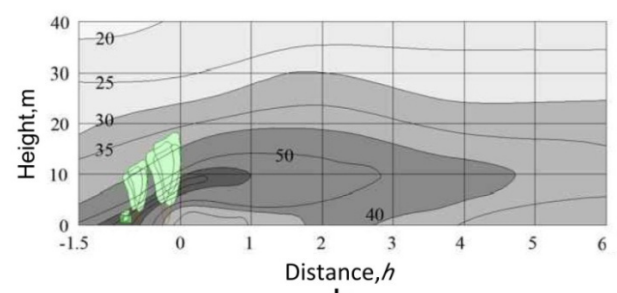

$\mathrm{b}$

Fig. 1. CO dispersion by vegetation shelterbelts, in \%. Upper plot: permeable structure (one or two rows of trees); lower plot: dense structure (two or three rows of trees, with shrubbery infill). $h$ is the shelterbelt height; figures show CO concentration in \%, assuming that $100 \%$ is the CO concentration at $1,5 \mathrm{~m}$ above the edge of the road.

From a comparison of $\mathrm{CO}$ dispersion schemes in Fig. 1 and diagrams of the CO concentration reduction behind the green planting belts in Fig. 2 it follows that the most advantageous in the system "carriageway - the green strip" are linear-strip structures of green plantings of a dense non-blown structure. Their gas-resistant efficiency is $30 \%$ greater than that of blown structures due to a more evident insulating capacity.

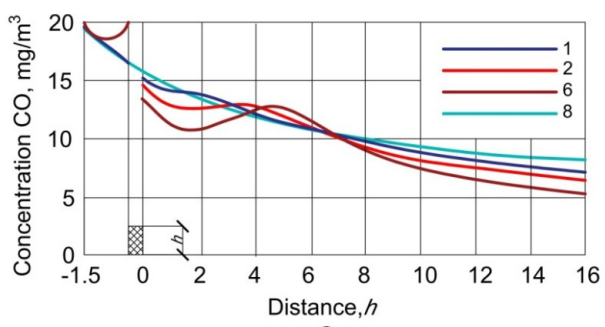

a

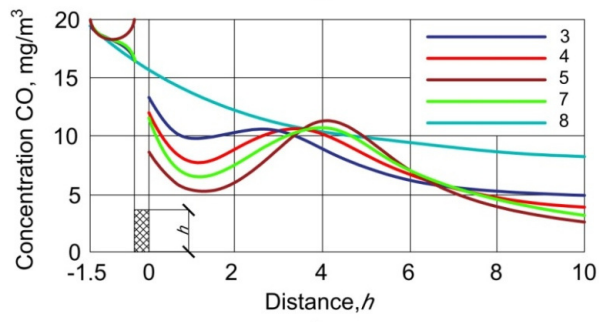

$\mathrm{b}$

Fig. 2. The $\mathrm{CO}$ air concentration reduction by the green plantation belts with permeable structure - height of $9 \mathrm{~m}$ (a) and thick structure - height of $14 \mathrm{~m}$ (b). $1-K=0,17 ; 2-0,28 ; 3-$ 0,$23 ; 4-0,32 ; 5$ и $6-1 ; 7-0,41 ; 8$ - scattering of CO in the exposed territory. $h$-height of the belt, $\mathrm{m}$. 
Thus, if in real conditions the amount of the absorbed ingredient is more determined by the trees and shrubs dendrological composition and the degree of the belt permeability, then its dispersion effectiveness, as follows from the experiment results, depends significantly on its height and density. According to this effect, equations 1 and 2 are transformed as follows:

$$
\begin{aligned}
& \text { at } x \leq 30 m q_{x}=q_{0}\left(1-\frac{\omega}{100}\right) \mathrm{e}^{-0,0413 x} \\
& \text { at } x>30 m q_{x}=0,29 q_{0}\left(1-\frac{\omega}{100}\right)-0,14(x-30)
\end{aligned}
$$

where $\omega$ is the gas-protective efficiency of the green plantation belt, $\%$, determined by the formula obtained empirically:

$$
\omega=48 \cdot(1+0,016 h) \cdot K^{\frac{2}{3}}
$$

where $h$ is the height of green plantations, $\mathrm{m}(h \geq 5) ; K$ is the openness coefficient.

The data of Table 1 show that to efficiently protect pedestrian ways and adjacent areas from vehicles' exhausts, it is necessary to use green planting shelter-belts with the width of $15 . .30 \mathrm{~m}$ of impermeable or equally open work. To expand the gas protective zone, it is needed to include multi-row plantings of high growing trees (maple trees-white, black,

\begin{tabular}{|c|c|c|c|c|}
\hline Shelterbelt structure & $\begin{array}{c}\text { Height, } \\
{[\mathrm{m}]}\end{array}$ & $\begin{array}{l}\text { Width, } \\
{[\mathrm{m}]}\end{array}$ & $\begin{array}{c}\text { Density } \\
\text { rate }\end{array}$ & $\begin{array}{c}\text { Protective } \\
\text { Efficiency, } \\
{[\%]}\end{array}$ \\
\hline \multirow{3}{*}{$\begin{array}{l}\text { One row of } \\
\text { trees, one row } \\
\text { of shrubbery }\end{array}$} & $5 \ldots 8$ & \multirow{3}{*}{$4 \ldots 6$} & \multirow{3}{*}{$0.2 \ldots 0.4$} & $17 \ldots 28$ \\
\hline & $8 \ldots 10$ & & & $18 \ldots 29$ \\
\hline & $10 \ldots 15$ & & & $20 \ldots 32$ \\
\hline \multirow{3}{*}{$\begin{array}{l}\text { Two rows of } \\
\text { trees, one row } \\
\text { of shrubbery }\end{array}$} & $5 \ldots 8$ & \multirow{3}{*}{$6 \ldots 8$} & \multirow{3}{*}{$0.3 \ldots 0.6$} & $23 \ldots 27$ \\
\hline & $8 \ldots 10$ & & & $24 \ldots 38$ \\
\hline & $10 \ldots 15$ & & & $26 \ldots 42$ \\
\hline \multirow{3}{*}{$\begin{array}{l}\text { Two rows of } \\
\text { trees, two rows } \\
\text { of shrubbery }\end{array}$} & $5 \ldots 8$ & \multirow{3}{*}{$8 \ldots 10$} & \multirow{3}{*}{$0.4 \ldots 0.7$} & $28 \ldots 41$ \\
\hline & $8 \ldots 10$ & & & $29 \ldots 43$ \\
\hline & $10 \ldots 15$ & & & $32 \ldots 47$ \\
\hline \multirow{3}{*}{$\begin{array}{l}\text { Three to four } \\
\text { rows of trees, } \\
\text { two rows of } \\
\text { shrubbery }\end{array}$} & $5 \ldots 8$ & \multirow[b]{3}{*}{$10 \ldots 15$} & \multirow[b]{3}{*}{$0.5 \ldots 0.8$} & $33 \ldots 45$ \\
\hline & $8 \ldots 10$ & & & $34 \ldots 47$ \\
\hline & $10 \ldots 15$ & & & $37 \ldots 51$ \\
\hline \multirow{3}{*}{$\begin{array}{c}\text { Five to six rows } \\
\text { of trees, two } \\
\text { rows of } \\
\text { shrubbery }\end{array}$} & $5 \ldots 8$ & \multirow[b]{3}{*}{$20 \ldots 30$} & \multirow[b]{3}{*}{$0.7 \ldots 1.0$} & $37 \ldots 48$ \\
\hline & $8 \ldots 10$ & & & $38 \ldots 50$ \\
\hline & $10 \ldots 15$ & & & $42 \ldots . .55$ \\
\hline
\end{tabular}
Canadian, maple trees, et al.) and shrubbery.

Table 1. Reduction of CO concentration by green shelterbelts (in \%)

The graphical dependence of the gas-protective efficiency of the green plantation belts on the density characterized by the coefficient of openness is obtained according to the results of researches on models and is shown in Fig. 3. In the course of the curves, it can be seen that with an increase in the belts density, their gas-protective effect first sharply 
increases, and then a less intense decrease in the CO concentration is observed. This should be taken into account when, in the presence of engineering dividing belts for laying utility networks, where the conditions of their operation do not prescribe tree planting, the width of the street is insufficient to set the most dense woody and shrub plantations. In such conditions it is necessary, within the limits of the street transverse profile, to form belts of green plantations of optimum density with $K=0.5 \ldots 0.6$ corresponding to the sections of the steepest position of the curves in the Fig. 3.

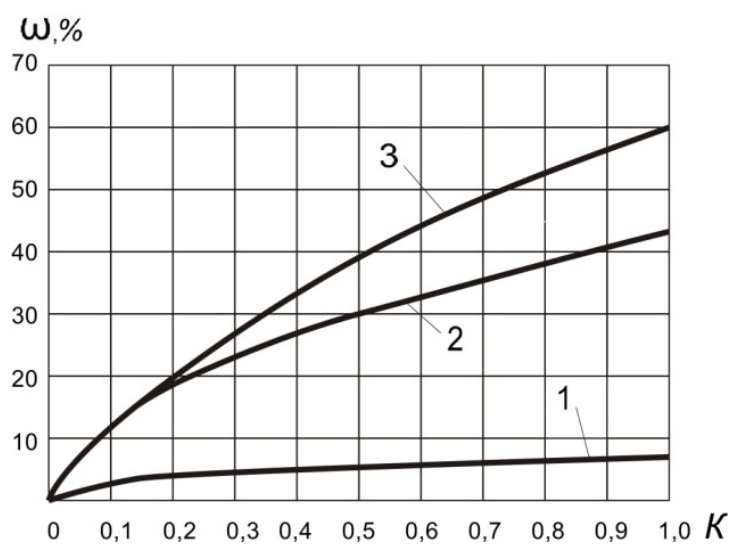

Fig. 3. Dependence of protective efficiency $(\omega, \%)$ of shelterbelts against gaseous air-pollutants from their density $(K)$ and height (h). Line 1: $h=1.6 \mathrm{~m}$ (shrubbery); line 2: $h=9 \mathrm{~m}$; line $3: h=14$ $\mathrm{m}$.

It should be also noted that in the formation of roadside belts along the two sides in the form of vertical "walls" above the traffic area, as in the street canyon, reverse circulation of air flow appears [11], "the process of accumulation of car emissions over the road because of the close arrangement of the first rows of trees" occurs as the result, whose height reaches $15 \mathrm{~m}$ [12]. Therefore, in order to exclude the possibility of the car exhaust closed circulation occurrence the rows of plants nearest to the carriageway on both sides of the road must be represented by shrubs in the form of a two-tier hedge and trees with a low crown. In the succeeding rows, the plants' height should be gradually increased.

\section{Summary}

Among the major structural characteristics of the environment protective belts are in the row spacing and the space between the rows. The values of these parameters greatly influence the stand canopy density in the rows, density of biomass, and the frontal structure of the belt in general. At the same time, the most branching and leafing is typical for the most illuminated edge trees and shrubbery rows consisting of major species and constituting a "gradual" [3] form of cross-section in the shelter-belt. Therefore, it is possible to widen the stripes of trees and shrubbery only by increasing the number of their inner rows, the degree of their biomass density being modest, as a rule. It is obvious that the biomass density of the green belt under expansion is increasing in indirect ratio to increasing the row number and the total width of woody plants section but to a far lesser degree.

Plantings for the greening of urban roads and streets should be fast-growing, sufficiently gas-resistant and capable to absorb harmful substances. In this connection, when adjusting the species composition of trees and shrubbery, it is recommended to plant field maple, silver and black poplar trees, horse chestnut, cotoneaster, hawthorns, spindle-wood, nine bark, and snow-berry [13]. In this case, it is necessary to take into account the competitive relations of individual species among themselves in the process of growth, to distinguish main, additional and decorative (finishing) ones. 
When choosing a plant assortment in environmental protection belts, it should also be taken into account that their aerodynamic characteristics, gas and noise protection effectiveness significantly depend on the structural features of the various breeds trees and shrubs crowns, as well as on their age and seasonal variability.

\section{References}

1. B. I. Kochurov, I. V. Ivashkina, Moscow cityscapes: from traditional to harmonized and balanced ones, Urban ecology, 1, 6-11 (2012).

2. B. I. Kochurov, I. V. Ivashkina, Moscow cityscapes and their special transformations, Urban ecology, 2, 48-54 (2015).

3. A. V. Gorodkov, Guidelines for environment-protection urban gardening (SPbGASU Publ., Saint Petersburg, 1998).

4. F. L. Serebrovskii, Ventilation of residential territories (Stroiizdat Publ., Moscow, 1985).

5. O. V. Chernyshenko, Absorption capacity and pollution-resistance of trees in urban terrains, Thesis ... of Doctor of Biology Sciences, Moscow, 2001.

6. Ya. A. Smalko, Wind-sheltering characteristics of green belts of various structures (USSR Publ., Kiev, 1963).

7. A. R. Konstantinov, L. R. Struzer, Green shelterbelts and land productivity (Gidrometeoizdat Publ., Leningrad, 1974).

8. V. V. Balakin, Study of sheltering efficiency of green belts of various structure against air-pollutants along thoroughfare streets, Matter of mechanical aid and technology in construction operations: collection of studies (VPI Publ., Volgograd, 1978).

9. V. F. Sidorenko, V. V. Balakin, Yu. G. Feldman, Hygiene and sanitation, 4, 106-108 (1978).

10. V. V. Balakin, V. F. Sidorenko, Scientific trends and prospects in 21th century: collection of scientific articles, Ufa, MTSII ”OMEGA-SAINS“'Publ., 2016.

11. Jong-Jin Baik, Jae-Jin Kim, Journal of Applied Meteorology, 38 (11), 1576-1589 (1999).

12. V. P. Podolskii, A. N. Kanishchev and V. N. Rudaev, Book of abstracts from the $5^{\text {th }}$ scientific/technical conference in Moscow, Russia, Feb 1-2, 2001, Moscow: MADI (GTU) Publ., 2001.

13. T. V. Ivchenko, R. A. Romanova, E. Yu. Korotkova, Town/city gardening against airpollution by car emissions, Urban ecology, 1, 30-33 (2014). 